\title{
DEVELOPMENT OF STRAIN PREDICTION MODELS FOR CONCRETE ROADS
}

\author{
Revathi G M ${ }^{1}$, N. Aravind ${ }^{2}$, Radhakrishna ${ }^{3}$, B.G. Raghavendra Prasad ${ }^{4}$ \\ ${ }^{1}$ Post Graduate Student, Department of Civil Engineering, $R V$ College of Engineering, Bangalore \\ ${ }^{2}$ Research Scholar, Department of Civil Engineering, $R V$ College of Engineering, Bangalore \\ ${ }^{3}$ Associate Dean, Department of Civil Engineering, $R V$ College of Engineering, Bangalore \\ ${ }^{4}$ Research Scholar, Department of Civil Engineering, $R V$ College of Engineering, Bangalore
}

\begin{abstract}
The performance of concrete roads can be monitored in different ways. In order to achieve the continuous and long term monito ring of the pavements, the use of sensor technology is very effective. There are various types of techniques reported to monitor the pavement distress in concrete roads. Sensors are commonly used in the pavements to determine the stress, strain, temperature etc. In this paper, mathematical models are developed using the data reported by Federal Highway Authority (FHWA). The relation between the strain and voltage are used to develop the models. The models are validated each other and also with an independent set of experimental data reported by FHWA. Further, fibre reinforced concrete prisms of grade M40 were cast and cured. The strains in the prisms were measured experimentally by using piezoelectric sensors which were later correlated with the predicted values by the model. The predicted strains were in line with the actual strains measured in the laboratory. The proposed models would be useful in predicting the strains in the concrete structures, roads and white topping roads with the input of single experimental data.
\end{abstract}

Keywords: Continuous and long term monitoring, Sensor Technology, Piezoelectric Sensors, Mathematical models. $* * *$

\section{INTRODUCTION}

Pavement is the permanent superimposed layers of different materials laid over the natural subgrade soil to sustain vehicular or pedestrian traffic loads. It is subsequently distributed to the subgrade soils. The pavement is classified as flexible and rigid pavements based on their structural performance [1-5]. Flexible pavements construction has low initial cost but shows early signs of distresses from the day it is constructed. The rigid pavement on the other hand have increased initial cost by about $25 \%$ to that of flexible pavement but the life cycle cost is economical to that of the flexible pavement [6-9]. The usual materials used for flexible and rigid pavements are bitumen and cement concrete respectively.

The performance of cement concrete pavement is affected by the adverse conditions of stresses and weathering hence undergoes deterioration [10]. In order to enhance the life of the pavement up to its design life, continuous monitoring of the pavement is very much essential [11]. The performance of Cement concrete pavements can be evaluated in many different ways based on the external defects visible on the structure due to the internal distresses experienced by them [12].

The continuous and long term monitoring of the pavements is possible by incorporating the sensors technology. The sensors can be used to measure the strain experienced by the concrete pavements, extent of crack formation, temperature stresses etc
[13]. Piezoelectric sensors are popular, inexpensive and simple method of measuring the voltage generated in concrete road for various strains. The name is comprised of two parts, piezo, which is derived from the Greek word for pressure, and electric from electricity. The rough translation is, therefore, pressure - electric effect. In a piezoelectric material, the application of a force or stress results in the development of a charge in the material. This is known as the direct piezoelectric effect. Conversely, the application of a charge to the same material will result in a change in mechanical dimensions or strain. This is known as the indirect piezoelectric effect. The piezoelectric sensor converts a physical parameter to an electric output i.e. in terms of voltage output, electrical impedance etc [14]. Later these voltages can be correlated with the strains in the concrete. Ultimately, the strain in concrete can be estimated without much effort. This would be helpful in monitoring concrete pavements [15-16].

Federal Highway Administration [17] has generated extensive data which correlates voltage with the corresponding strain in concrete loads at various temperatures. However there are no models developed so far which can predict the strain in concrete road with the input of single experimental data. This paper addresses this issue. 


\subsection{Scope of the Research}

In the present study, an attempt is made to embed piezoelectric sensors in concrete to measure the strains. Two numerical models were developed using the data extracted from the report - Smart Pavement Monitoring System by Federal Highway Administration in 2013 [17]. The models were validated using independent set of data and experimental data generated independently in the laboratory.

\section{2 .MATERIALS AND METHODS}

Natural river sand and granite aggregates were used as fine and coarse aggregates in making concrete. The specific gravity and fineness modulus of river sand were 2.6 and 2.9. The grain size distribution of sand is given in Figure 1. The specific gravity of coarse aggregates used was 2.63 whose grain size distribution is as shown in Figure 2. Ordinary Portland cement of 53 grades was used for the study having specific gravity of 3.15 .

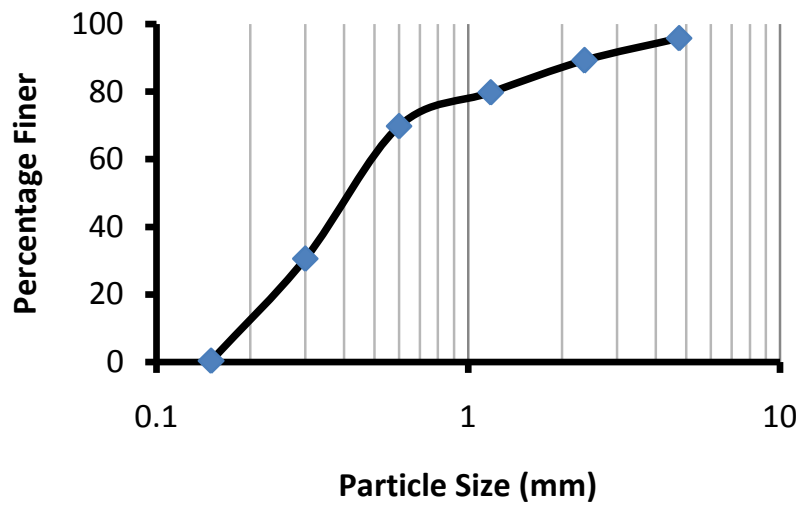

Fig 1: Grain Size Distribution of Fine Aggregates

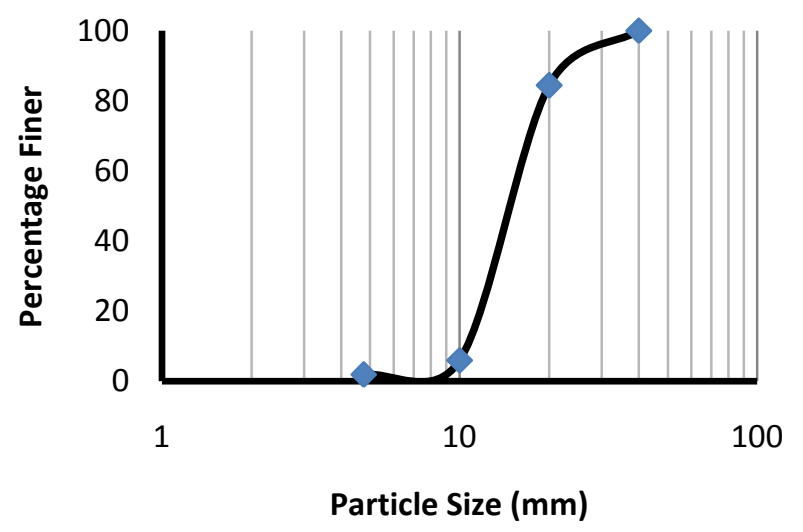

Figure 2: Grain Size Distribution of coarse aggregates
Four series of concrete of Grade M 40 was proportioned using with and without fibres as per IRC: 44-2008 [18] and final quantities arrived are shown in Table 1.

Table 1: Mix Proportions of Various Concretes

\begin{tabular}{|c|c|c|c|c|c|}
\hline Index & $\begin{array}{c}\text { Cement } \\
\mathrm{kg} / \mathrm{m}^{3}\end{array}$ & $\begin{array}{c}\text { Wa- } \\
\text { ter } \\
\mathrm{kg} / \mathrm{m}^{3}\end{array}$ & $\begin{array}{c}\text { Sand } \\
\mathrm{kg} / \mathrm{m}^{3}\end{array}$ & $\begin{array}{l}\text { Coarse } \\
\text { Aggregate } \\
\text { kg/m } \mathbf{m}^{3} \\
\end{array}$ & $\begin{array}{l}\text { Fi- } \\
\text { bers } \\
\text { dosage } \\
\text { kg/m }\end{array}$ \\
\hline $\begin{array}{l}\text { Plain } \\
\text { Concrete }\end{array}$ & 372 & 186 & 668 & 1103 & 0 \\
\hline $\begin{array}{l}\text { FRC } \\
\text { with } \\
\text { Fibrofor }\end{array}$ & 372 & 186 & 668 & 1103 & 1.00 \\
\hline $\begin{array}{l}\text { FRC } \\
\text { with } \\
\text { Concrix }\end{array}$ & 372 & 186 & 668 & 1103 & 3.75 \\
\hline $\begin{array}{l}\text { HFRC } \\
\text { with } \\
\text { Fibrofor } \\
\text { and } \\
\text { Concrix }\end{array}$ & 372 & 186 & 668 & 1103 & $\begin{array}{c}(0.25 \\
+ \\
2.81) \\
=3.06\end{array}$ \\
\hline
\end{tabular}

At the water-cement ratio of 0.4 , the slump value of concrete was 0 for plain concrete. To maintain the slump value of $50 \pm$ $5 \mathrm{~mm}$, super plasticizer of Master Polyheed was used. The dosage of superplasticizer maintains the required workability. The optimum dosage was found out to be $0.45 \%$ as per the Marsh cone test conducted. Fresh concrete of all the four types were used to cast cylinders of $150 \mathrm{~mm}$ diameter and 300 $\mathrm{mm}$ height. Piezoelectric sensors were embedded into concrete cylinder in fresh condition at the height of $150 \mathrm{~mm}$. The cylinders were cured for 28 days before being tested. The concrete cylinders were tested for compression. The strains at various loads were recorded by using demec gauge. Simultaneously, the voltages in the piezoelectric sensors were recorded using multimeter.

\subsection{Data Extraction}

Federal Highway Administration (FHWA) has experimentally generated the data which relates the voltage output of the piezoelectric sensors and strain gauges. The strains developed in the concrete beams were recorded in the laboratory at various temperatures. The same data was extracted and shown in Figures 3 and 4 [14]. These variations in these graphs are same but recorded using two distinctly different sensing devices Piezoelectric sensor and strain gauge. 


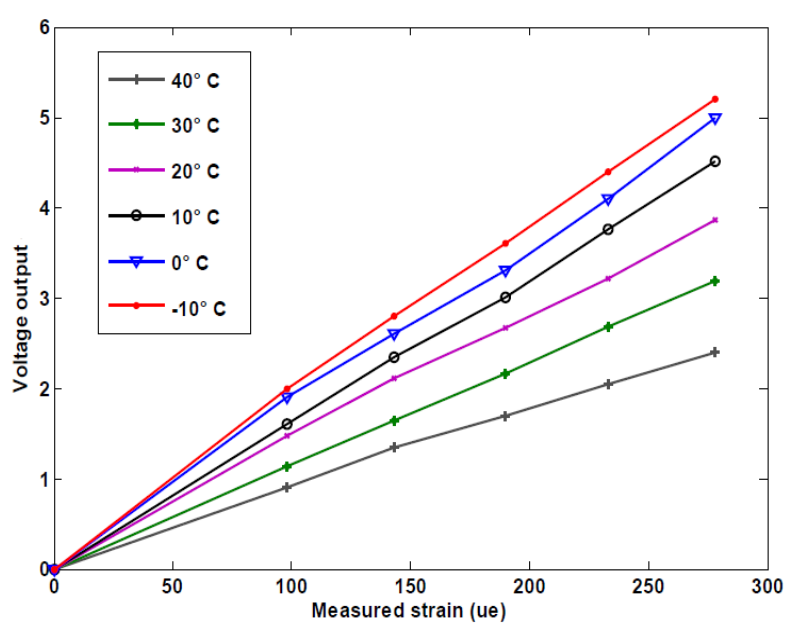

Fig 3: Strain v/s Voltage using Piezoelectric Sensor

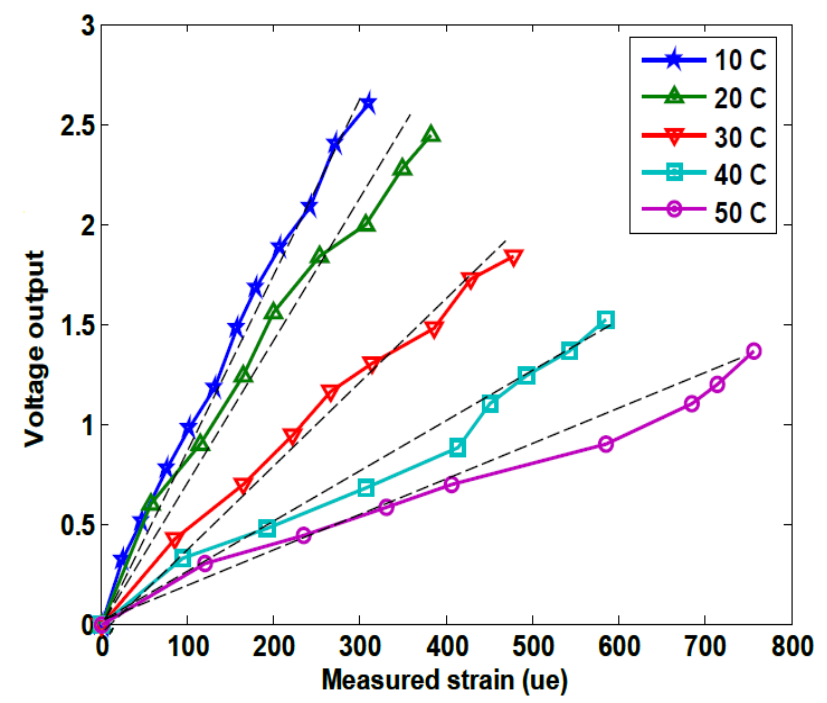

Fig 4: Strain v/s Voltage using Strain Gauge

\subsection{Necessity of Numerical Model}

A rational, rapid and simple method to predict strain in concrete is an important event in monitoring the concrete pavements. In practice, the strain in concrete may vary with temperature and other conditions. It is practically challenging to estimate the strain in concrete for different temperatures with fewer amounts of data. Even at the same temperature, concrete experiences different strains at different loading conditions. Hence, there is a need for the development of numerical model to predict strain. A numerical model would be one in which strain in concrete can be estimated at the given voltage generated by sensor, with single input of experimental data, for the given set of conditions. This can be done by normalising the strains in concrete by various voltage values. In this direction data extracted from FHWA are very useful.

\section{NUMERICAL MODEL}

To develop the numerical model, strain at voltage at $1 \mathrm{mV}$ is considered reference for normalisation. This reference strain in concrete is arbitrary and has no other significance. The resulting functional relation developed using the data given in Figure 3 is represented in Equation 1. The same is graphically represented in Figure 5 with $\mathrm{R}^{2}=0.9952$.

$$
\left\{\frac{S}{S_{V=1 m V}}\right\}=1.055 \mathrm{~V}
$$

Where $\mathrm{V}$ is voltage output by sensors, $\mathrm{S}_{\mathrm{v}=1 \mathrm{mV}}$ is experimentally obtained strain for the voltage of $1 \mathrm{mV}$ and $\mathrm{S}$ is strain for any load applied at different temperatures.

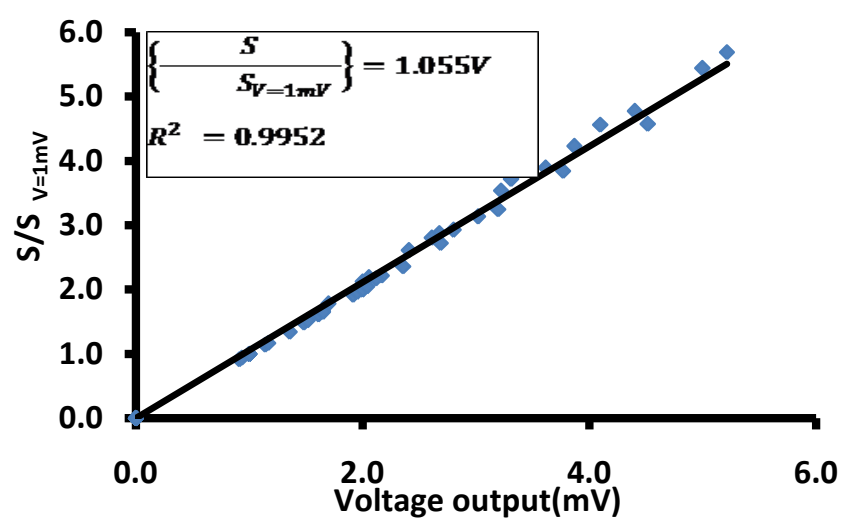

Fig 5: Strain Prediction model developed from the data obtained from Piezoelectric Sensor

The functional relation developed using the data given in Figure 4 is shown below (Equation 2).

$$
\left\{\frac{S}{S_{V=1 \mathrm{mV}}}\right\}=1.079 \mathrm{~V}
$$

The same model is graphically represented in Figure 6 with $\mathrm{R}^{2}=0.9737$. In both the cases, the models possess very high coefficient of regression( $R$ ) having $S_{@ V=1 m v}$ as common reference. 


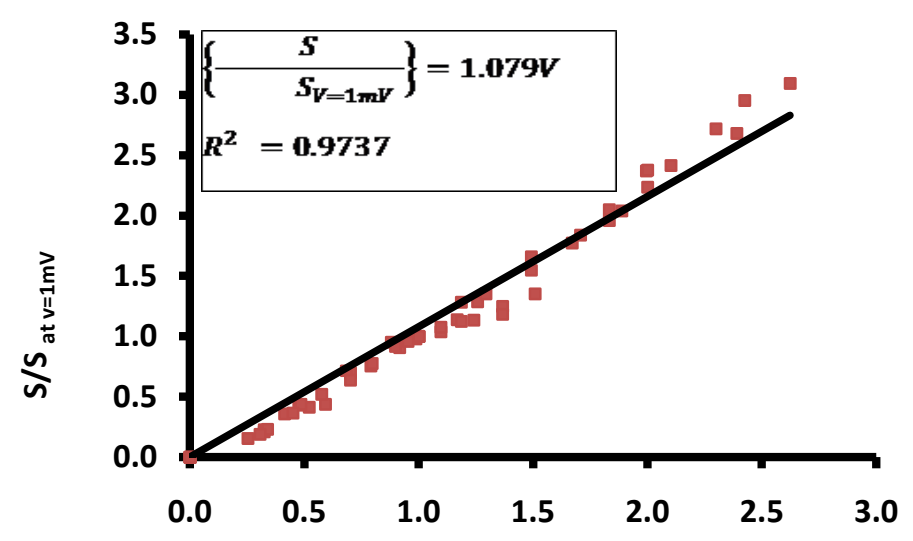

Equation 1 is used to predict the values given in Figure 4 and tabulated in Table 2. It can be seen the table that there is close match between the data extracted from FHWA and predicted. This reinforces the possibility of using this model for practical applications. Further, equation 2 is used to predict the values given in Figure 3 and tabulated in Table 3. It can be seen in the table that there is close match between the data extracted from FHWA and predicted.

\section{Voltage output(mV)}

Fig 6: Strain Prediction Model developed from the data obtained from Strain Gauge.

Table 2: Comparison of data from Equation 1 and data from Figure 4

\begin{tabular}{|c|c|c|c|c|c|}
\hline $\begin{array}{c}\text { Temperature } \\
\left({ }^{0} \mathrm{C}\right)\end{array}$ & $\begin{array}{c}\text { Strain } \\
(\mu \varepsilon)\end{array}$ & $\begin{array}{c}\text { Voltage out- } \\
\text { put }(\mathrm{mV})\end{array}$ & $\begin{array}{l}\mathrm{S} / \mathrm{S}_{\text {at }} \\
\mathrm{V}=1 \mathrm{mV}\end{array}$ & $\begin{array}{c}\text { Predicted } \\
\text { strains }(\mu \varepsilon)\end{array}$ & $\begin{array}{l}\text { Percentage } \\
\text { Error }\end{array}$ \\
\hline \multirow{9}{*}{-10} & 0 & 0.00 & 0.0 & 0 & 0.00 \\
\hline & 98 & 0.91 & 0.9 & 105 & -7.44 \\
\hline & 100 & 0.94 & 0.9 & 108 & -7.56 \\
\hline & 106 & 1.00 & 1.0 & 115 & -7.90 \\
\hline & 143 & 1.36 & 1.3 & 156 & -9.12 \\
\hline & 189 & 1.70 & 1.8 & 195 & -3.06 \\
\hline & 226 & 2.00 & 2.1 & 230 & -1.57 \\
\hline & 233 & 2.06 & 2.2 & 236 & -1.35 \\
\hline & 278 & 2.41 & 2.6 & 277 & 0.31 \\
\hline \multirow{9}{*}{0} & 0 & 0.00 & 0.0 & 0 & 0.00 \\
\hline & 85 & 1.00 & 1.0 & 92 & -7.90 \\
\hline & 98 & 1.14 & 1.1 & 105 & -7.86 \\
\hline & 100 & 1.17 & 1.2 & 108 & -7.76 \\
\hline & 143 & 1.65 & 1.7 & 152 & -6.47 \\
\hline & 174 & 2.00 & 2.0 & 184 & -5.85 \\
\hline & 189 & 2.17 & 2.2 & 200 & -5.62 \\
\hline & 233 & 2.69 & 2.7 & 248 & -6.52 \\
\hline & 278 & 3.20 & 3.2 & 295 & -6.20 \\
\hline \multirow{5}{*}{10} & 0 & 0.00 & 0.0 & 0 & 0.00 \\
\hline & 66 & 1.00 & 1.0 & 71 & -7.90 \\
\hline & 98 & 1.48 & 1.5 & 105 & -7.91 \\
\hline & 100 & 1.52 & 1.5 & 108 & -7.71 \\
\hline & 137 & 2.00 & 2.1 & 142 & -3.76 \\
\hline
\end{tabular}




\begin{tabular}{|c|c|c|c|c|c|}
\hline $\begin{array}{l}\text { Temperature } \\
\left({ }^{\circ} \mathrm{C}\right)\end{array}$ & $\begin{array}{c}\text { Strain } \\
(\mu \varepsilon)\end{array}$ & $\begin{array}{l}\text { Voltage out- } \\
\text { put }(\mathrm{mV})\end{array}$ & $\begin{array}{l}\mathrm{S} / \mathrm{S}_{\text {at }} \\
\mathrm{V}=1 \mathrm{mV}\end{array}$ & $\begin{array}{c}\text { Predicted } \\
\text { strains }(\mu \varepsilon)\end{array}$ & $\begin{array}{l}\text { Percentage } \\
\text { Error }\end{array}$ \\
\hline & 143 & 2.12 & 2.2 & 150 & -5.26 \\
\hline & 189 & 2.68 & 2.9 & 190 & -0.29 \\
\hline & 233 & 3.22 & 3.5 & 229 & 1.79 \\
\hline & 278 & 3.87 & 4.2 & 275 & 1.25 \\
\hline \multirow{9}{*}{20} & 0 & 0.00 & 0.0 & 0 & 0.00 \\
\hline & 61 & 1.00 & 1.0 & 65 & -7.90 \\
\hline & 98 & 1.61 & 1.6 & 105 & -7.90 \\
\hline & 100 & 1.65 & 1.7 & 108 & -7.91 \\
\hline & 121 & 2.00 & 2.0 & 131 & -7.96 \\
\hline & 143 & 2.36 & 2.4 & 154 & -7.99 \\
\hline & 190 & 3.02 & 3.1 & 197 & -3.96 \\
\hline & 233 & 3.77 & 3.8 & 246 & -5.78 \\
\hline & 277 & 4.52 & 4.6 & 295 & -6.52 \\
\hline \multirow{9}{*}{30} & 0 & 0.00 & 0.0 & 0 & 0.00 \\
\hline & 51 & 1.00 & 1.0 & 55 & -7.90 \\
\hline & 98 & 1.92 & 1.9 & 105 & -7.92 \\
\hline & 100 & 1.95 & 2.0 & 107 & -7.37 \\
\hline & 103 & 2.00 & 2.0 & 110 & -6.69 \\
\hline & 143 & 2.61 & 2.8 & 144 & -0.62 \\
\hline & 189 & 3.31 & 3.7 & 182 & 3.86 \\
\hline & 232 & 4.10 & 4.6 & 225 & 3.03 \\
\hline & 277 & 5.00 & 5.4 & 275 & 0.82 \\
\hline \multirow{8}{*}{40} & 0 & 0.00 & 0.0 & 0 & 0.00 \\
\hline & 49 & 1.00 & 1.0 & 53 & -7.90 \\
\hline & 98 & 2.00 & 2.0 & 105 & -7.90 \\
\hline & 100 & 2.04 & 2.0 & 108 & -7.53 \\
\hline & 143 & 2.80 & 2.9 & 148 & -3.36 \\
\hline & 190 & 3.62 & 3.9 & 190 & -0.28 \\
\hline & 233 & 4.40 & 4.8 & 232 & 0.44 \\
\hline & 278 & 5.21 & 5.7 & 275 & 1.10 \\
\hline
\end{tabular}

Table 3: Comparison of data from Equation 2 and data from Figure 3

\begin{tabular}{|c|r|r|r|r|r|}
\hline $\begin{array}{c}\text { Temperature } \\
\left({ }^{\circ} \mathrm{C}\right)\end{array}$ & \multicolumn{1}{c|}{$\begin{array}{c}\text { Strain } \\
(\mu \varepsilon)\end{array}$} & \multicolumn{1}{c|}{$\begin{array}{c}\text { Voltage out- } \\
\text { put }(\mathrm{mV})\end{array}$} & \multicolumn{1}{c|}{$\begin{array}{c}\text { S/S } \\
\mathrm{V}=1 \mathrm{mV}\end{array}$} & $\begin{array}{c}\text { Predicted } \\
\text { Strain }(\mu \varepsilon)\end{array}$ & $\begin{array}{c}\text { Percentage } \\
\text { Error }\end{array}$ \\
\hline \multirow{4}{*}{10} & 0.00 & 0.00 & 0.00 & 0.00 & 0.00 \\
\cline { 2 - 6 } & 22.64 & 0.32 & 0.23 & 34.12 & -50.69 \\
\cline { 2 - 6 } & 41.51 & 0.52 & 0.42 & 54.97 & -32.42 \\
\cline { 2 - 6 } & 75.47 & 0.79 & 0.75 & 83.39 & -10.49 \\
\cline { 2 - 6 } & 98.11 & 0.99 & 0.98 & 104.23 & -6.24 \\
\hline
\end{tabular}




\begin{tabular}{|c|c|c|c|c|c|}
\hline $\begin{array}{c}\text { Temperature } \\
\left({ }^{\circ} \mathrm{C}\right)\end{array}$ & $\begin{array}{c}\text { Strain } \\
(\mu \varepsilon)\end{array}$ & $\begin{array}{l}\text { Voltage out- } \\
\text { put }(\mathrm{mV})\end{array}$ & $\begin{array}{l}\mathrm{S} / \mathrm{S}_{@} \\
\mathrm{~V}=1 \mathrm{mV}\end{array}$ & $\begin{array}{l}\text { Predicted } \\
\text { Strain }(\mu \varepsilon)\end{array}$ & $\begin{array}{l}\text { Percentage } \\
\text { Error }\end{array}$ \\
\hline & 100.00 & 1.00 & 1.00 & 105.53 & -5.53 \\
\hline & 128.30 & 1.19 & 1.28 & 125.08 & 2.51 \\
\hline & 154.72 & 1.49 & 1.55 & 157.30 & -1.67 \\
\hline & 177.36 & 1.67 & 1.77 & 176.26 & 0.62 \\
\hline & 203.77 & 1.89 & 2.04 & 198.99 & 2.35 \\
\hline & 223.69 & 2.00 & 2.24 & 211.00 & 5.67 \\
\hline & 241.51 & 2.10 & 2.42 & 221.74 & 8.19 \\
\hline & 267.92 & 2.39 & 2.68 & 252.06 & 5.92 \\
\hline & 309.43 & 2.62 & 3.09 & 276.71 & 10.58 \\
\hline \multirow{11}{*}{20} & 0.00 & 0.00 & 0.00 & 0.00 & 0.00 \\
\hline & 56.60 & 0.59 & 0.44 & 80.70 & -42.56 \\
\hline & 100.00 & 0.80 & 0.78 & 108.25 & -8.25 \\
\hline & 116.98 & 0.92 & 0.91 & 124.72 & -6.61 \\
\hline & 129.03 & 1.00 & 1.00 & 136.13 & -5.50 \\
\hline & 166.04 & 1.26 & 1.29 & 171.18 & -3.10 \\
\hline & 252.83 & 1.83 & 1.96 & 249.42 & 1.35 \\
\hline & 305.66 & 1.99 & 2.37 & 271.44 & 11.20 \\
\hline & 306.55 & 2.00 & 2.38 & 272.25 & 11.19 \\
\hline & 350.94 & 2.30 & 2.72 & 313.01 & 10.81 \\
\hline & 381.13 & 2.43 & 2.95 & 330.12 & 13.38 \\
\hline \multirow{12}{*}{30} & 0.00 & 0.00 & 0.00 & 0.00 & 0.00 \\
\hline & 83.02 & 0.41 & 0.36 & 101.08 & -21.75 \\
\hline & 100.00 & 0.47 & 0.43 & 116.15 & -16.15 \\
\hline & 162.26 & 0.70 & 0.70 & 171.38 & -5.62 \\
\hline & 222.64 & 0.95 & 0.96 & 232.90 & -4.61 \\
\hline & 231.87 & 1.00 & 1.00 & 244.62 & -5.50 \\
\hline & 264.15 & 1.17 & 1.14 & 285.64 & -8.14 \\
\hline & 313.21 & 1.29 & 1.35 & 316.39 & -1.02 \\
\hline & 384.91 & 1.49 & 1.66 & 364.73 & 5.24 \\
\hline & 426.42 & 1.71 & 1.84 & 417.47 & 2.10 \\
\hline & 426.42 & 1.71 & 1.84 & 417.47 & 2.10 \\
\hline & 475.47 & 1.83 & 2.05 & 448.22 & 5.73 \\
\hline \multirow{7}{*}{40} & 0.00 & 0.00 & 0.00 & 0.00 & 0.00 \\
\hline & 90.57 & 0.32 & 0.21 & 147.49 & -62.85 \\
\hline & 100.00 & 0.34 & 0.23 & 154.56 & -54.56 \\
\hline & 188.68 & 0.49 & 0.44 & 221.19 & -17.23 \\
\hline & 309.43 & 0.68 & 0.72 & 311.31 & -0.61 \\
\hline & 411.32 & 0.88 & 0.95 & 401.42 & 2.41 \\
\hline & 432.29 & 1.00 & 1.00 & 456.06 & -5.50 \\
\hline
\end{tabular}




\begin{tabular}{|c|r|r|r|r|r|}
\hline $\begin{array}{c}\text { Temperature } \\
\left({ }^{\circ} \mathrm{C}\right)\end{array}$ & $\begin{array}{c}\text { Strain } \\
(\mu \varepsilon)\end{array}$ & \multicolumn{1}{c|}{$\begin{array}{c}\text { Voltage out- } \\
\text { put }(\mathrm{mV})\end{array}$} & \multicolumn{1}{c|}{$\begin{array}{c}\mathrm{S} / \mathrm{S}_{\Theta} \\
\mathrm{V}=1 \mathrm{mV}\end{array}$} & $\begin{array}{c}\text { Predicted } \\
\text { Strain }(\mu \varepsilon)\end{array}$ & \multicolumn{1}{c|}{$\begin{array}{c}\text { Percentage } \\
\text { Error }\end{array}$} \\
\hline \multirow{6}{*}{} & 449.06 & 1.10 & 1.04 & 499.75 & -11.29 \\
\cline { 2 - 6 } & 490.57 & 1.24 & 1.13 & 565.29 & -15.23 \\
\cline { 2 - 6 } & 539.62 & 1.37 & 1.25 & 622.66 & -15.39 \\
\cline { 2 - 6 } & 584.91 & 1.51 & 1.35 & 688.20 & -17.66 \\
\hline \multirow{5}{*}{50} & 0.00 & 0.00 & 0.00 & 0.00 & 0.00 \\
\cline { 2 - 6 } & 100.00 & 0.25 & 0.16 & 170.06 & -70.06 \\
\cline { 2 - 6 } & 120.75 & 0.31 & 0.19 & 205.37 & -70.07 \\
\cline { 2 - 6 } & 233.96 & 0.45 & 0.37 & 302.00 & -29.08 \\
\cline { 2 - 6 } & 332.08 & 0.57 & 0.52 & 386.59 & -16.42 \\
\cline { 2 - 6 } & 407.55 & 0.70 & 0.64 & 471.12 & -15.60 \\
\cline { 2 - 6 } & 584.91 & 0.90 & 0.92 & 603.99 & -3.26 \\
\cline { 2 - 6 } & 637.39 & 1.00 & 1.00 & 672.45 & -5.50 \\
\cline { 2 - 6 } & 686.79 & 1.10 & 1.08 & 736.87 & -7.29 \\
\cline { 2 - 6 } & 716.98 & 1.19 & 1.12 & 797.26 & -11.20 \\
\cline { 2 - 6 } & 754.72 & 1.37 & 1.18 & 918.10 & -21.65 \\
& & & & & \\
\hline
\end{tabular}

The models were also validated with an independent set of experimental data for plain and fibre reinforced concrete. The comparison is given in Figure 7. It can be noticed that the values of experimental strains are in close agreement with the predicted values using both Equations 1 and 2. This reconfirms the confidence of the models to be used in monitoring the concrete pavements.

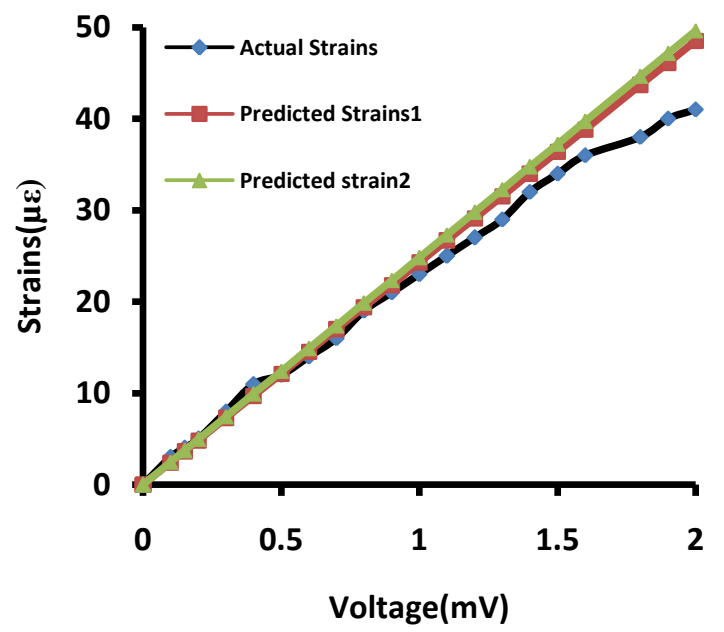

Fig 7: Comparison of Actual and predicted Strains from the Model developed

\section{VALIDATION OF THE MODEL}

The model from Equation 1 for a given set of materials and conditions, the strain at a specified voltage of $1 \mathrm{mV}$ is to be determined experimentally. Using this data as input parameter the strain at any given voltage can be calculated.

\section{CONCLUDING REMARKS}

From the limited study on the developing strain prediction models, the following conclusions can be drawn.

- It is possible to develop numerical models using the data generated and reported by FHWA for predicting strains in concrete.

- The models were validated with each other and with the independent set of experimental results obtained.

- The proposed models would be useful in predicting the strains in the concrete structures, roads and white topping roads with the input of single experimental data.

\section{REFERENCES}

[1]. V.K.Sinha et.al., Whitetopping - A Cost-Effective Rehabilitation Alternative For Preserving Bituminous Pavements On Long-Term Basis, IRC Journal, Volume 10,Paper No.538, pp 538,2007

[2]. IRC: SP: 83-2008, Guidelines for Maintenance, Repairs \& Rehabilitation of Cement Concrete Pavements

[3]. Lee, E. B., Ibbs, W., Roesler, J et.al, Construction productivity and constraints for concrete pavement rehabilitation in 
urban corridors, Transportation Research Record, 1712,

Transportation Research Board, pp 13-22.

[4]. Mitesh D. Patel et.al, White topping as a Rehabilitation Method: A Case Study of Budhel-ghogha road, International Journal of Advanced Engineering Research and Studies, Vol. I, Issue IV, July-Sept., 2012, pp-31-35

[5]. Atakilti Gidyelew Bezabih et.al, Comparative Study Of

Flexible And Rigid Pavements For Different Soil And Traffic

Conditions, IRC Journal, Volume 10,Paper No 554.

[6]. Thomas L. Weinmann, Andrew E. Lewis, Shiraz D. Tayabji, Pavement Sensors Used At Accelerated Pavement Test Facilities, Journal of Basic and Applied Scientific Research, Volume 2,pp 203-209, 2011

[7]. Julie M. Vandenbossche, Performance Analysis of Ultrathin Whitetopping Intersections on US-169, Transportation Research Record 1823, Paper No. 03-4437, pp 18,2008.

[8]. Tritsch, S., "Whitetopping, Technique Revives Burgeoning Kansas Thoroughfare," Roads and Bridges, September 1995, pp. 52-55.

[9]. Sharmin Sultana and Mustaque Hossain,Thin "Whitetopping for Green Highways", Green Streets and Highways 2010: An Interactive Conference on the State of the Art and How to Achieve Sustainable Outcomes, Proceedings of the Green Streets and Highways 2010 Conference

[10]. Juan Quintana, Francisco Carrion, Paul Garnica et.al., Long Term Monitoring of a Continuous Reinforced Pavement Highway,

[11]. R. Roque, L. A. Myers, and B. Birgisson, Evaluating Measured Tire Contact Stresses to Predict Pavement Response and Performance, Journal of the Transportation Research Board, 1716, pp. 73-81, 2000.

[12]. A. Loulizi, I. L. Al-Qadi, S. Lahouar, and T. E. Freeman, "Data Collection and Management of the Instrumented Smart Road Flexible Pavement Sections", Journal of the Transportation Research Board, 1769,pp. 142-151, 2001.

[13]. J. M. McQueen and D. H. Timm, Part 2: Pavement Monitoring, Evaluation, and Data Storage: Statistical Analysis of Automated Versus Manual Pavement Condition Surveys, Journal of the Transportation Research Board, 1940, pp. 5362, 2005.

[14]. Yoshihiro et.al, Crack detection in concrete elements using piezoelectric cables, Smart Materials and Structures, Volume 5, pp. 196-208, 2006.

[15]. Wen Hui Duan, Quan Wang and Ser Tong Quek, Applications of Piezoelectric Materials in Structural Health Monitoring and Repair: Selected Research Examples, Materials 2010, Volume 3, pp-5169-5194.

[16]. Xiaochun Li, Embedded Sensors in Layered Manufacturing, Materials and Structures, Volume 3, pp. 196-208, 2003

[17]. Smart Pavement Monitoring Systems, Federal Highway Administration, Publication No: FHWA-HRT-12-072, May 2013.

[18]. IRC: 44-2008, Tentative Guidelines for Cement Concrete Mix Design for Pavements.

\section{BIOGRAPHIES}

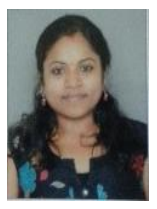

Revathi G M, Civil Engineering graduate, presently pursuing M.Tech in Highway Technology at R.V. College of Engineering, Bangalore - 560 059

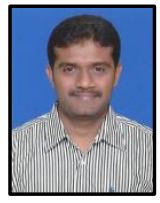

Er. Aravind N, Civil Engineering graduate with Postgraduate degree in Highway Engineering from Bangalore University. Pursuing Ph.D. in Highway Engineering. Has over 7.5 years professional experience in Highway sectors

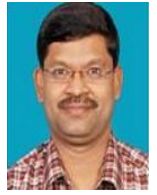

Dr. Radhakrishna is presently the Associate Professor and Dean for PG Studies. Nodal Officer - TEQIP II (Civil and Environmental), has published more than 50 research papers in journals/conferences. He has guided two $\mathrm{PhDs}$ and presenting guiding 5 more. His areas of interests include alternative building materials, rigid pavement etc. He is the Associate editor of five international reputed journals.

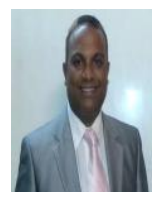

Er. B.G. Raghavendra Prasad is presently serving as Executive Engineer at Bruhat Bengaluru Mahanagara Palike (BBMP). He is graduated from BMS Evening College of Engineering and Post graduation from University Visveswaraya College of Engineering. He is perusing $\mathrm{PhD}$ at $\mathrm{R} \mathrm{V}$ College of Engineering in the area of rigid pavements. 